David M. Ansley MD, J. Patrick O'Connor MD, Pamela M. Merrick BSN, Donald R. Ricci MD,* John Dolman MD, Paul Kapnoudhis MD

\title{
On line ST-segment analysis for detection of myocardial ischaemia during and after coro- nary revascularization
}

Purpose: A paucity of information exists to validate the accuracy and reliability of ECG monitoring in the operating room or ICU. The purpose of this study was to determine the accuracy, sensitivity, specificity, and predictive values of the Marquette ECG monitor for detection of perioperative myocardial ischaemia (PMI) as measured by ST segment changes in a high risk population.

Methods: Monitoring for PMI in 28 patients scheduled for aortocoronary bypass surgery was done with the Cardiodata $P R^{\circledR}$ ambulatory continuous electrocardiography (ACECG) monitor lead $V_{s}$, and compared with lead $V_{5}$ of the Marquette ${ }^{\circledR}$ Series 7000 ECG/ Surgical operating room monitor, and ECG/Resp ICU monitor. The Marquette lead $V_{5}$ was evaluated using current criteria for the assessment of diagnostic tests including concordance, sensitivity, specificity, positive and negative predictive values, false positive and false negative rates and compared with the ACECG monitor which served as the reference or "gold standard." Agreement beyond chance between the two methods was assessed using the Kappa statistic.

Results: Of the 53 observation data points, 27 were defined as ischaemic episodes by ACECG. Concordance between lead $V_{5}$ in each system was $83 \%$ (44/53 episodes). Discordance was $17 \%$ (9/53 episodes), predominantly in the postbypass interval

\section{Key words}

HEART: myocardial ischaemia;

SURGERY: cardiac;

MONITORING: noninvasive, electrocardiography.

From the Departments of Anaesthesia and Medicine*,

Vancouver Hospital and Health Sciences Centre, University of British Columbia, Vancouver, British Columbia, Canada.

Address correspondence to: Dr. David M. Ansley,

Department of Anaesthesia, Room 3200, 3rd floor, 910 West

10th Avenue, Vancouver, BC, Canada V5Z 4E3.

Presented at the 68th Congress of the International Anaesthesia Research Society, March 5-9, 1994, Orlando, Florida, USA.

Accepted for publication July 4, 1996.
(77\%, 7/9; $P=0.0184)$. The incidences of false negatives and false positives for Marquette lead $V_{5}$ was $26 \%(7 / 27)$ and 7.7\% (2/26), respectively. The sensitivity and specificity of the Marquette was 0.74 and 0.92. Positive predictive value was 0.91 , negative predictive value was 0.77 , and Kappa statistic was 66\%.

Conclusion: Automated ST segment analysis with the Marquette ${ }^{\circledR}$ Series 7000 monitoring system demonstrates good diagnostic accuracy, moderate sensitivity, and high specificity. However, clinically significant false negative and false positive rates of ischaemia detection are associated with its use. especially in the postoperative period.

Objectif: Peu de données nous permettent de valider la précision et la fiabilité du monitorage électrocardiographique en salle d'opération et à l'unité des soins intensifs. Cette étude avait pour but de déterminer dans une population à haut risque, la précision, la sensibilité, la spécificité et la valeur prédictrice du moniteur d'ECG Marquette destiné à la détection de l'ischémie myocardique périopératoire (IMP) telle que mesurée par les altérations du segment ST.

Méthodes: Chez 28 patients programmés pour une chirurgie de revascularisation myocardique, l'IMP était monitorisée par électrocardiographie ambulatoire continue (ECGAC) à l'aide d'un appareil Cardiodata $P R^{\circledast}$ en dérivation $V_{5}$, pour fin de comparaison à la dérivation $V_{5}$ d'un moniteur ECG de salle d'opération et d'un moniteur ECG/Resp de soins intensifs Marquette ${ }^{\circledR}$ Series 7000. La dérivation $V_{5} d u$ Marquette était comparée aux critères en vigueur pour l'évaluation des épreuves diagnostiques dont la concordance, la sensibilité, la spécificité, les valeurs prédictrices négatives et positives, le taux de faux positifs et de faux négatifs. L'accord entre les deux méthodes était évaluée par statistique Kappa.

Résultats: Des 53 épisodes observés, 27 ont été décrits par l'ECGAC comme des épisodes ischémiques. La concordance entre la dérivation $V_{5}$ de chaque système était $83 \%(44 / 53$ épisodes). La discordance était 17\% (9/53 épisodes), avec prédominance pendant l'intervalle post-CEC $(77 \%, 7 / 9 ; P=$ 0,0184). Avec le $V_{5}$ du Marquette, l'incidence de faux négatifs 
et de faux positifs était respectivement de $26 \%(7 / 27)$ et de 7,7\% (2/26). La sensibilité et la spécificité du Marquette étaient de 0,74 et de 0,92. La valeur prédictrice positive était 0,91 , et négative, 0,77. La statistique Kappa était calculée à $66 \%$.

Conclusion: L'analyse automatisée du segment ST avec un système de monitorage Marquette Series 7000 est précise, modérément sensible et hautement spécifique. Cependant, un taux cliniquement important de faux négatifs et de faux positifs est associé à son utilisation surtout à la période postopératoire.

The accurate detection of perioperative myocardial ischaemia in patients undergoing aortocoronary bypass surgery is clinically important. Up to $40 \%$ of patients scheduled for coronary revascularization develop life threatening postoperative ischaemia that is associated with an increased need for pharmacological support and/or need for intra-aortic balloon counterpulsation. ${ }^{1}$ Silent, asymptomatic myocardial ischaemia may be common and may identify a high risk patient population.

The electrocardiogram remains the least expensive, most readily available, and specific monitor for the detection of myocardial ischaemia. However, there exists a relative paucity of information to validate the accuracy of ECG monitoring for the detection of ischaemia occurring in patients in the operating room (OR) or intensive care unit (ICU). This has recently been stressed by the American Heart Association task force on practice standards for electrocardiographic monitoring in special care units. ${ }^{2}$

Clinical studies have documented the usefulness of ambulatory, continuous ECG monitoring (ACECG) for the determination of the natural history of ischaemia in populations at risk. ${ }^{3,4}$ Hollenburg has recently determined the applicability and reliability of ACECG to detect myocardial ischaemia in patients undergoing aortocoronary bypass surgery. ${ }^{4}$ This study established the suitability of ACECG as a "gold standard" technique for detection of perioperative myocardial ischaemia in this setting, when rigid criteria are applied.

This study compared ST-segment analysis of the Marquette ${ }^{\circledR}$ Series 7000 ECG/Surgical (OR) and ECG/ Respiratory (ICU) monitors with ACECG using the Cardiodata ${ }^{\circledR}$ MK 4 analysis system for detection of perioperative myocardial ischaemia in a high risk patient population undergoing coronary artery revascularization. The purpose was to determine the accuracy of the Marquette ECG monitor for the detection of perioperative myocardial ischaemia (PMI) in a high risk population.

\section{Methods}

Following institutional ethics committee approval and informed patient consent, 28 patients scheduled for ACBP surgery were studied. Preoperative evaluation included invasive cardiac angiography and routine ECG. Patients taking digoxin, or those with preoperative left bundle branch block, left ventricular hypertrophy, or intraventricular conduction delay were excluded from this study. Patients continued their anti-anginal medications up to $90 \mathrm{~min}$ preoperatively. All patients received $0.06 \mathrm{mg} \cdot \mathrm{kg}^{-1}$ lorazepam $\mathrm{po}, 90 \mathrm{~min}$ before surgery.

A two channel AM ambulatory ECG recorder, Cardiodata $P R^{\circledR}$ (flat frequency response $\pm 3 \mathrm{db}$ from $0.05-100 \mathrm{~Hz}$ ) continuously monitored bipolar lead $V_{5}$ from two to four hours preoperatively, intraoperatively, and for $24 \mathrm{hr}$ after surgery. Standard silver/silver chloride $(\mathrm{Ag} / \mathrm{AgCl})$ electrodes were applied by a trained ECG technician, following appropriate skin preparation to avoid loss of ECG lead contact. The ECG signal was calibrated and standardized prior to data collection in each patient. The Marquette ${ }^{\circledR}$ Series 7000 ECG/ Surgical (OR) module and ECG/Resp (ICU) module (flat frequency response $\pm 3 \mathrm{db}$ from $0.05-40 \mathrm{~Hz}$ and $0.05-100 \mathrm{~Hz}$, respectively) monitored lead $\mathrm{V}_{5}$, intraand postoperatively, for $24 \mathrm{hr}$. This $V_{5}$ lead was positioned so that its contact was immediately adjacent to its bipolar $\mathrm{V}_{5}$ counterpart. A fixed analysis point $(60 \mathrm{msec}$ after the $\mathbf{J}$ point) was determined for each patient, on arrival in the operating room, and ICU, respectively. Lead specific ST trends for lead $V_{5}$ were reproduced using this monitor's graphic software.

Anaesthesia consisted of $3-10 \mu \mathrm{g} \cdot \mathrm{kg}^{-1}$ sufentanil and isoflurane, 0.5-2.0\%, in air/oxygen $\left(\mathrm{FIO}_{2}=0.5\right)$. Surgery was conducted with hypothermic cardiopulmonary bypass $\left(28^{\circ} \mathrm{C}\right)$ and membrane oxygenator. Cold crystalloid or blood cardioplegia $\left(8-10^{\circ} \mathrm{C}\right)$ was employed for myocardial protection. Nitroglycerin, $i v$, was used only to treat episodes of myocardial ischaemia during the study interval. The criteria for detection of myocardial ischaemia included: (1) new horizontal or downsloping ST segment depression $\geq 1 \mathrm{~mm}$ for more than one minute; or (2) ST segment elevation $\geq 1.5 \mathrm{~mm}$ at the $\mathrm{J}$ point $+60 \mathrm{msec}$, lasting more than one minute in duration. Myocardial infarction was diagnosed by the following criteria : CK-MB > 100 IU with new $\mathrm{Q}$ waves or evolving $\mathrm{T}$ wave changes on serial ECGs. ${ }^{5}$

The Cardiodata ${ }^{\circledR}$ MK4 analysis system was used for playback to generate ACECG reports. These reports were reviewed independently by a cardiologist (DR) and an anaesthetist (DMA) for diagnosis of myocardial ischaemia. This was aided by the use of patient diaries that noted timing of intraoperative events, including defibrillation and the use of cautery. The Marquette 
TABLE Comparison of Marquette ECG lead $V_{5}$ and ACECG lead $V_{5}$

\begin{tabular}{lllll}
\hline & & \multicolumn{3}{c}{ “Gold Standard" Ischaemia assessed by ACECG } \\
\cline { 2 - 5 } & & Ischaemic & Non-ischaemic & Total \\
\hline Ischaemia assessed & Positive & $20^{a}$ & $2^{b}$ & 22 \\
by Marquette & Negative & $7^{c}$ & $24^{d}$ & 31 \\
\hline & & 27 & 26 & 53 \\
\hline
\end{tabular}

$a^{a}=$ \# of study periods with ischaemia and positive.

${ }^{b}=\#$ of study periods without ischemia and positive.

$c=\#$ of study periods with ischaemia and negative.

$d=$ \# of study periods without ischaemia and negative.

Marquette: Sensitivity $=0.74 ;$ Specificity $=0.92$.

Positive Predictive Value $=0.91$ (excellent, high proportion of correctly predicted ischaemic study periods)

Negative Predictive Value $=0.77$ (good, moderately high proportion of correctly predicted non-ischaemic study periods).

Accuracy $=0.83$ (agreement between diagnostic tests)

Kappa $=0.66$ (agreement beyond chance).

reports generated in the intra- and postoperative periods were reviewed by two anaesthestists (DMA, JPO). Where discrepancies existed, an attempt to reach a consensus on interpretation was made between observers.

Ischaemic episodes as determined by ACECG were examined for timing, duration and severity. Data comparisons were made using the presence or absence of ischaemia in the Marquette monitors at corresponding time periods intra- and postoperatively. Data from both Marquette monitors were combined for comparison to data from the ACECG, because the total number of ischaemic episodes was small. The Marquette ECG lead $\mathrm{V}_{5}$ was evaluated and compared with the ACECG by applying current criteria for the assessment of diagnostic tests: sensitivity, specificity, positive and negative predictive values, and Kappa statistic. ${ }^{6-8}$ (Appendix) False positive and false negative rates for the prebypass versus postbypass intervals were compared by chi-square analysis. $P<0.05$ was considered statistically significant.

\section{Results}

The ACECG and Marquette monitoring was complete and available for comparison in all 28 patients enrolled in this study. Twenty-seven ischaemic episodes were detected in 17 patients by ACECG using a bipolar $V_{5}$ lead. Prebypass ischaemia occurred in nine patients $(31.5 \%)$ : arrival $=3(10 \%) ;$ pre-CPB $=6(21 \%)$. Postoperative ischaemia occurred in 13 patients (46.4\%): OR only (post CPB to end of surgery ) $=4$ (14.3\%); OR and ICU (on admission) $=2(7.1 \%)$; ICU only (admission to $24 \mathrm{hr}$ post CPB) $=7(25 \%)$. Consensus could not be reached between the reviewers regarding interpretation of four episodes of ST elevation. These changes met diagnostic criteria but the cardi- ologist felt they were not ischaemic. These episodes were eliminated from further analysis.

The Table summarizes the comparison of Marquette ECG lead $V_{5}$ with the ACECG bipolar lead $V_{5}$. The overall concordance between leads was $83 \%$ (44/53). The overall discordance between leads was $17 \%(9 / 53)$. The intraoperative pre-bypass discordance rate was $22 \%$ (2/9 episodes @ 15 and 102 min pre-bypass). The postbypass discordance increased to 77\% (7/9 episodes @ 11 to 14.5 hours postbypass), $P=0.0184$. The incidences of false negatives and false positives for Marquette lead $\mathrm{V}_{5}$ were $26 \%(7 / 27)$ and $7.7 \%(2 / 26)$, respectively. Agreement beyond chance between the two monitors was found to be $66 \%$, as measured by the Kappa statistic. The Table shows highly acceptable values for the criteria generally used to evaluate the usefulness of a diagnostic test. ${ }^{6-8}$

\section{Discussion}

This study evaluated the Marquette ${ }^{\circledR}$ Series 7000 operating room and ICU ECG monitors for the detection of perioperative myocardial ischaemia in patients undergoing aortocoronary bypass surgery. The principal findings included: (1) Marquette lead $V_{5}$ and ACECG bipolar lead $V_{5}$ were in agreement $83 \%$ of the time, $66 \%$ of the time beyond chance; (2) Marquette lead $V_{5}$ falsely diagnosed episodes as negative for ischaemia $26 \%$ of the time; (3) more disagreement between Marquette lead $\mathrm{V}_{5}$ and bipolar lead $\mathrm{V}_{5}$ occurred in the first 24 hr postbypass; (4) Marquette lead $V_{5}$ sensitivity, specificity, positive and negative predictive values were all within acceptable limits.

Early postoperative myocardial ischaemia has recently been linked to the development of adverse cardiac events. ${ }^{1}$ Much of the research conducted in this area has 
relied on the use of ECG technology to characterize this phenomenon. The preoperative pattern of ischaemia may identify patients at high risk for the development of adverse cardiac sequelae (myocardial infarction, unstable angina, congestive cardiac failure). ${ }^{9}$ Potentially reversible, prolonged postoperative ST segment depression precedes the development of postoperative myocardial infarction.

The accuracy and reliability of ECG technology in the perioperative assessment of myocardial ischaemia has been questioned. ${ }^{10}$ The technology is still evolving, having moved from intermittent sampling to continuous on-line monitoring (including real time or retrospective review), as well as computerized ST segment analysis. The American Heart Association has requested review of this area, in an effort to standardize equipment for use in an operating room or ICU. ${ }^{2}$ This comes with the recognition that real, but subtle differences exist between monitoring systems, and the development of their use for ischaemia detection is a recent event.

In this study we studied three monitoring systems. Their frequency responses ranged from 0.05 to $100 \mathrm{~Hz}$, a range that would allow for accurate reproduction of the QRST complex. The frequency response of the intraoperative monitor used was not as wide as the "gold standard." The frequency limit of 0.05 to $40 \mathrm{~Hz}$ still permits accurate processing of the ST segment. All monitors operate in the "diagnostic mode," avoiding another source of false positive/false negative distortion of the ST segment as reported by Slogoff $e t$ al. ${ }^{11}$

The methodological criteria used to evaluate diagnostic tests has been previously established. ${ }^{6-8}$ This includes the definition of the "gold standard" based on definitive pathological diagnoses, explicit criteria, and reproducible results. On this basis, ACECG was defined as the reference "gold standard" for this study. This decision was based on the following: (1) mechanical and electric measures of myocardial ischaemia show equal sensitivity in vivo; 12 (2) ST segment depression is accompanied by a reduction in coronary blood flow as measured by positron emission tomography: ${ }^{13}$ (3) transient ST depression is a rare finding in the normal population: ${ }^{14}$ (4) when rigorous criteria for ECG interpretability and patient exclusion are used, it is a reliable and suitable monitor of myocardial ischaemia in the setting of cardiac surgery; ${ }^{4}$ and (5) its use in previous clinical studies. ${ }^{1.15}$ Our data analysis adopted this recommended approach. The observers were blinded to the interpretation of the "gold standard" results before comparisons were made of episodes detected by the Marquette monitors at similar intra- and postoperative times. Using this method, evaluation bias is reduced, and clinical usefulness better defined. ${ }^{6.7}$
Based on our criteria, the two lead systems demonstrate a highly acceptable degree of concordance of 0.83 . The discordance between unipolar Marquette lead $\mathrm{V}_{5}$ and bipolar ACECG lead $\mathrm{V}_{5}$ was different in the operating room and ICU. Of importance, the discordance between systems increased in the postbypass period. The unipolar Marquette lead $V_{5}$ underestimated myocardial ischaemia at a time when patients are at greatest risk for its development and sequelae. Based on our findings, a clinician could expect false negative signalling for nearly a quarter of ischaemic episodes, and false positive signals about eight per cent of the time. We consider these rates to be clinically important because of their potential impact on patient therapy.

These findings require cautious interpretation. Despite the attempt to control for similarities in monitors and lead placement, subtle differences may exist. For accurate QRST complex recording, the shaving of body hair, cleansing of skin with isopropyl alcohol, abrasion of skin to enhance lead contact, and the use of stable $\mathrm{Ag} / \mathrm{AgCl} \mathrm{ECG}$ electrodes have been shown to be beneficial. This was the case with respect to use of ACECG monitoring, since the electrode system was applied by ECG technicians well versed in this procedure. Despite the application of Marquette ECG monitor electrodes in the operating room by the anaesthetists involved in the study, this rigid protocol may not have been adhered to. We wanted to simulate clinical conditions as far as possible. This could have introduced inaccuracies in the assessment of the ECG between systems and/or among patients. This would have made it impossible to reach perfect agreement between systems. In addition, since these leads were adjacent to one another, it is possible, given the strong vectorial nature of the ST segment, that a change in the position of the sensing electrode attendant with chest wall rotation following sternotomy and retraction could introduce additional experimental error.

The increase in postoperative discordance is an important finding. Recently, it has been recommended that ischaemic changes be confirmed with a calibrated ECG. ${ }^{16}$ Inappropriate ST segment values could be produced if measurement of the isoelectric point occurred in the $P$ wave as the PR interval shortens during tachycardia, or if measurement occurred in the $S$ wave during prolongation of the QRS interval. The variations in heart rate and change in QRST morphology seen at this time may require more frequent resetting of measurement points than what we did in this study. Study patients were not observed by the investigators continuously in the postoperative period. We did not reset these measurement points to accommodate such changes, other than at the initiation of monitoring on arrival in the ICU. The potential for ST baseline drift during this time due 
to factors other than myocardial ischaemia may be a confounding variable. The small number of ischaemic episodes observed limits this study and makes the interpretation of this result difficult. This finding will have to be confirmed by additional study with application of strict experimental criteria to accommodate change in heart rate or QRS morphology during this perioperative interval.

A larger discrepancy existed between what the ACECG detected and what the cardiologist interpreted as myocardial ischaemia. Controversy exists over interpretation of changes in the ST segment as a measure of myocardial ischaemia. Postural changes, tachycardia, hypertension, sympathetic system discharge, hyperventilation, change in left ventricular dimension, change in intraventricular conduction, and drug therapy can all produce ST segment shift that mimics myocardial ischaemia. ${ }^{17}$ These events may be encountered frequently in the operating room. This concern was raised by the cardiologist reviewing ACECG reports, who insisted on rigid criteria for their interpretation. We wanted to maintain a rigid interpretation of myocardial ischaemia and consensus could not be reached with respect to four episodes of ST elevation. Had our criteria been changed, it is possible that the frequency of ischaemic events might have been higher. However, specificity would have been reduced.

The use of ACECG monitoring allows for playback and retrospective review of the entire ECG profile over time (full disclosure). This capability to store ECG data, is not available in the Marquette monitors used in this study. However, the disadvantage of ACECG monitoring is the lack of real time display. The Marquette Series modules provides microcomputer based ST segment analysis, in the form of three lead ST trend and their mathematical sum in the form of a trend line. The ST segment data are displayed every four minutes. The data analysed were lead specific $\left(V_{5}\right)$ ST segment shift from isoelectric, trended for display of $1,4,8$, and $24 \mathrm{hr}$ periods. It is possible that interpretative differences exist because of the effects of data compression seen in the replay of ST segment trends for intervals greater than one hour. Newer digital Holter technology is starting to find its way into the operating room. ${ }^{18}$ Its development would allow for data storage and processing of trend lines as well as actual display of abnormal ECG complexes. Combined with the ability to reject artifact, these systems will provide a distinct advantage over that presently available for clinical use.

Physicians caring for patients undergoing aortocoronary bypass surgery should be aware of the usefulness and limitations of ECG monitors to detect myocardial ischaemia with accuracy and reliability in the OR and
ICU. This study has defined the limits of accuracy of the Marquette ${ }^{\circledR}$ Series 7000 operating room and ICU modules. Based on standard criteria the $\mathrm{V}_{5}$ lead of this monitoring system is highly acceptable, however it does have clinically important false positive and false negative rates of ischaemia detection. Therapeutic decisions based on monitors which may fail to detect episodes of myocardial ischaemia, especially in the postoperative period, may be incorrect. This could inadvertently jeopardize patients' outcomes. One way to enhance this could be to change the number and location of monitoring leads. Altering the lead system position of the Marquette monitor to provide two bipolar precordial leads is possible and may provide more efficient online ischaemia detection. This deserves further evaluation in the setting of cardiac surgery.

\section{Acknowledgements}

The investigators wish to acknowledge the help of staff from the Department of Diagnostic Electrocardiography at the Vancouver Hospital and Health Sciences Centre whose assistance made this study possible.

\section{References}

1 Smith RC, Leung JM, Mangano DT, SPI Research Group. Postoperative myocardial ischemia in patients undergoing coronary artery bypass graft surgery. Anesthesiology 1991; 74: 464-73.

2 Mirvis DM, Berson AS, Goldberger $A L$, et al. Instrumentation and practice standards for electrocardiographic monitoring in special care units. A report for health professionals by a Task Force of the Council on Clinical Cardiology, American Heart Association. Circulation 1989; 79: 464-71.

3 Gottleib SO, Weisfeldt ML, Ouyang P, Mellits ED, Gerstenblith $G$. Silent ischemia as a marker for early unfavorable outcomes in patients with unstable angina. $\mathrm{N}$ Engl J Med 1986; 314: 1214-9.

4 Hollenburg $M$. Reliability of the continuous ECG after cardiopulmonary bypass and CABG surgery. J Card Surg 1994; 9: 410-2.

5 Graeber GM, Shawl FA, Head HD, et al. Changes in serum creatine kinase and lactate dehydrogenase caused by acute perioperative myocardial infarction and by transatrial cardiac surgical procedures. J Thorac Cardiovasc Surg 1986; 92: 63-72.

6 Sheps $S B$, Schechter $M T$. The assessment of diagnostic tests. A survey of current medical research. JAMA 1984; 252: 2418-22.

7 Schechter MT, Sheps SB. Diagnostic testing revisited: pathways through uncertainty. Can Med Assoc J 1985; 132: 755-60.

8 Department of Clinical Epidemiology and Biostatistics, 
McMaster University Health Sciences Centre. How to read clinical journals: II. To learn about diagnostic tests. Can Med Assoc J 1981; 124: 703-10.

9 Knight AA, Hollenberg $M$, London MJ, et al. Perioperative myocardial ischemia: importance of the preoperative ischemic pattern. Anesthesiology 1988; 68: 681-8.

10 Hall RI, O'Regan N, Gardner M. Detection of intraoperative myocardial ischaemia - a comparison among electrocardiographic, myocardial metabolic, and haemodynamic measurements in patients with reduced ventricular function. Can J Anaesth 1995; 42: 487-94.

11 Slogoff S, Keats AS, David Y, Igo SR. Incidence of perioperative myocardial ischemia detected by different electrocardiographic systems. Anesthesiology 1990; 73 : 1074-81.

12 Watanabe S, Buffington $C W$. Speed and sensitivity of mechanical versus electrographic indicators to mild or moderate myocardial ischemia in the pig. Anesthesiology 1994; 80: 582-94.

13 Deanfield JE, Shea $M$, Ribiero $P$, et al. Transient ST-segment depression as a marker of myocardial ischemia during daily life. Am J Cardiol 1984; 54: 1195-200.

14 Deanfield JE, Ribiero P, Oakley K, Krikler S, Selwyn AP. Analysis of ST-segment changes in normal subjects: implications for ambulatory monitoring in angina pectoris. Am J Cardiol 1984; 54: 1321-5.

15 Leung JM, O'Kelly BF, Mangano DT, SPI Research Group. Relationship of regional wall motion abnormalities to hemodynamic indices of myocardial oxygen supply and demand in patients undergoing CABG surgery. Anesthesiology 1990; 73: 802-14.

16 Brooker S, Lownstein E. Spurious ST segment depression by automated ST segment analysis. J Clin Monit 1995; 11 : 186-9.

17 Marriott HJL. Practical Electrocardiography, 6th ed. Baltimore/London: Williams \& Wilkins, 1977: 290-318.

18 London MJ, Kaplan JA. Advances in electrocardiographic monitoring. In: Kaplan JA (Ed.). Cardiac Anaesthesia, 3rd ed. Philadelphia: WB Saunders \& Co., 1993: 299-341.

\section{Appendix}

Definitions and calculations for sensitivity, specificity, etc.

$$
\begin{aligned}
\text { Sensitivity }= & a / a+c \\
= & \text { proportion of study periods where } \\
& \text { ischaemia was present correctly identified } \\
& \text { by the Marquette } \\
\text { Specificity }= & d / b+d \\
= & \text { proportion of study periods without } \\
& \text { ischaemia correctly identified by the } \\
& \text { Marquette }
\end{aligned}
$$

Positive Predictive Value $=\mathrm{a} / \mathrm{a}+\mathrm{b}$

$=$ proportion of study periods with a positive Marquette when ischaemia is truly present

Negative Predictive Value $=d / c+d$

$=$ proportion of study periods with a negative Marquette when ischaemia is truly absent

Accuracy $=a+d / a+b+c+d$

$=$ the \# of true positives+the \# of true negatives / total \# of study periods tested $=$ agreement between diagnostic tests

$$
\begin{aligned}
\text { Kappa } & =\frac{O-C}{1-C} \\
& =O: \text { observed agreement } C: \text { chance agreement } \\
& =\text { agreement beyond chance }
\end{aligned}
$$

\section{REFERENCES}

Department of Clinical Epidemiology and Biostatistics, McMaster University. How to read clinical journals: II To learn about a diagnostic test. Can Med Assoc J 1981; 124: 703-10.

Schecter MT, Sheps $S B$. Diagnostic testing revisited: pathways through uncertainty. Can Med Assoc J 1985; 13: $755-60$

Dawson-Saunders B, Trapp RG. Basic and Clinical Biostatistics. Norwalk: Appleton \& Lange, 1990. 